\title{
Covid-19, prison crowding, and release policies
}

\author{
Safe release of prisoners could reduce community transmission
}

\author{
Paul L Simpson research fellow, Tony G Butler professor \\ Kirby Institute for Infection and Immunity in Society, University of New South Wales, Sydney, New South Wales, Australia
}

The emergence of covid-19 has again raised the issue of prisons as incubators of infectious diseases, highlighting that "prison health is public health." ${ }^{1}$ As far back as the 16th century typhus ("gaol fever") was responsible for high mortality in English prisons and community outbreaks when it "jumped the fence." Russian prison amnesties in 1997 and 2001 to relieve overcrowding released many prisoners with tuberculosis, contributing to an upturn in incidence that was subsequently linked to the disease's global re-emergence. ${ }^{3-5}$

The World Health Organization's guidelines on responding to covid-19 in prisons recommend that custodial and health agencies jointly engage in risk management, prevention and control, treatment, and information sharing. ${ }^{6}$ To prevent covid-19 outbreaks in our prisons and to protect those in custody, staff, and the wider community we also need more immediate action. This is especially pressing for overcrowded prisons; $59 \%$ of all countries worldwide having prison occupancy levels exceeding their officially reported capacity, ${ }^{7}$ and crowding is linked to adverse health outcomes and transmission of infection. ${ }^{18}$

However, no consensus exists on how to measure prisoner overcrowding. ${ }^{8}$ Prison cell spatial density (cell floor area per person) is the preferred metric since other measures such as "current prisoner population divided by reported prison capacity" or "number of square metres of the total prison floor area per person" are amenable to manipulation by prison authorities. $^{89}$

\section{Risks of overcrowding}

Our systematic review last year, despite finding the quality of most studies was poor or fair, yielded mostly consistent evidence that cell spatial density was associated with outcomes of infectious diseases, including tuberculosis, pneumococcal disease, and infectious dermatoses. ${ }^{8}$

We identified nine mediating factors for transmission of infectious disease related to cell spatial density: age, education level, pre-existing medical conditions (particularly chronic disorders), risk behaviours such as intravenous drug use, environmental ventilation, duration of incarceration, cell allocation, access to prison health service, and prison release to increase spatial separation among remaining prisoners. ${ }^{810}$
Alongside measures to improve prison hygiene and screening, testing, and isolation of cases, release strategies should be a public health priority given increasing evidence that covid-19 clusters starting in confined spaces are associated with wider community transmission. ${ }^{11}$ While prison release may be anathema to some, there are precedents. Iran has released up to 85000 prisoners in response to covid-19, prioritising those with pre-existing health conditions, ${ }^{12}$ and countries such as Afghanistan, Australia, Canada, Ethiopia, Germany, Israel, Poland, the UK, and the US are reportedly considering or have started this option. ${ }^{13}$

The mediating factors noted above, United Nations' guidance, ${ }^{1415}$ and current knowledge of covid-19, suggest we should be releasing a sizeable proportion of prisoners based on their risk to the community and vulnerability to covid-19 (for example through older age, having chronic health conditions, and intravenous drug use). Similarly, the poor health outcomes of indigenous peoples in countries such as the US, Australia, Canada, and New Zealand make these populations an obvious priority. Prisons with high spatial density should be prioritised for release programmes, ideally before any cases of covid-19 occur; controlling an outbreak is more costly than preventing one and will require contact tracing, isolating, and quarantining those released into community settings. Well managed programmes require health, social, and economic support for released prisoners as well as effective collaboration between health and justice departments and prisoner support organisations.

Citizens held in prisons and other detention facilities need to be considered as part of the broader public health response to covid-19 given their vulnerability to infection. Amid the upheaval associated with the covid-19 pandemic, realisation that community based alternatives to prison are both humane and in the broader public health interest may be a silver lining.

Competing interests: The BMJ has judged that there are no disqualifying financial ties to commercial companies. The authors declare no other interests. The BMJ policy on financial interests is here: https://www.bmj.com/sites/default/files/ attachments/resources/2016/03/16-current-bmj-education-coi-form.pdf.

Provenance and peer review: Not commissioned; externally peer reviewed. 
1 Kinner SA, Young JT, Snow K, etal . Prisons and custodial settings are part of a comprehensive response to COVID-19. Lancet Public Health 2020;5:e188-9. 10.1016/S2468-2667(20)30058-X. 32197116

2 Howard J. Prisons and Lazarettos. The state of the prisons in England and Wales. (First published 1777). Patterson Smith, 1973.

3 Stern V. Sentenced to die? The problem of TB in prisons in Eastern Europe and Central Asia. International Centre for Prison Studies, 1999.

4 Coker R. Detention and mandatory treatment for tuberculosis patients in Russia. Lancet 2001;358:349-50. 10.1016/S0140-6736(01)05587-8 11502311

5 Mercer AJ, Jacobs B, Moon S, Kynch J. Prisons and the tuberculosis epidemic in Russia. $J$ Int Dev 2003;15:559-7410.1002/jid.1003

6 World Health Organization. Preparedness, prevention and control of COVID-19 in prisons and places of detention. World Health Organization Regional Office for Europe, 2020.

7 Institute for Crime and Justice Policy Research. World prison brief online database, 27 Mar 2020. https://www.prisonstudies.org/highest-to-lowest/occupancy-level?field_region_ taxonomy_tid=All

8 Simpson PL, Simpson M, Adily A, Grant L, Butler T. Prison cell spatial density and infectious and communicable diseases: a systematic review. BMJ Open 2019;9:e026806. 10.1136/bmjopen-2018-026806 31340959
9 Gaes GG. The effects of overcrowding in prison. Crime Justice 1985;6:95-14610.1086/449105

10 Simpson PL, Simpson M, Butler T. Prison cell size and adverse health effects: potential mediating factors. Kirby Institute, Corrective Services New South Wales, 2016.

11 Nishiura H, Oshitani H, Kobayashi T, Yang Y, Hayashi K, Miyama T, Kinoshita R, et al. Closed environments facilitate secondary transmission of coronavirus disease 2019 (COVID-19). medRxiv 2020.02.28.20029272 [Preprint.]

12 Iran to release 70000 prisoners to prevent coronavirus spread. US News $2020 \mathrm{Mar} 9$. https://www.usnews.com/news/world-report/articles/2020-03-09/iran-to-release-70-000prisoners-to-prevent-coronavirus-spread

3 Institute for Crime and Justice Policy Research. News on covid-19 and prisons. $28 \mathrm{Ma}$ 2020. https://www.prisonstudies.org/news/news-covid-19-and-prisons

14 UNODC. Handbook on strategies to reduce overcrowding in prisons. United Nations Office on Drugs and Crime, 2010

15 UNODC. Handbook on prisoners with special needs. United Nations Office on Drugs and Crime, 2009.

Published by the BMJ Publishing Group Limited. For permission to use (where not already granted under a licence) please go to http://group.bmj.com/group/rights-licensing/ permissions 